\title{
La crítica del joven Lacan al paralelismo psicofísico en "De la Psicosis Paranoica en sus relaciones con la personalidad"
}

Young Lacan's criticism of the psychophysical parallelism in "De la psychose paranoïaque dans ses rapports avec la personnalité"

En su tesis de 1932 titulada "De la psicosis paranoica en sus relaciones con la personalidad", Jacques Lacan emprende una crítica, esparcida en diversos lugares de la misma, al paralelismo psicofísico defendido por la tradición psiquiátrica. En este contexto y como clave para explicar tanto las psicosis paranoicas como la paranoia de autocastigo del caso Aimée, el joven psiquiatra expondrá una versión propia del paralelismo, apoyándose en dos autores: Jakob Von Uexküll y Baruch Spinoza. Intentaremos destacar este recorrido así como las consecuencias de un paralelismo propiamente lacaniano.

Palabras clave: Paralelismo, psicosis, Umwelt, discordancia

*1 Universidad Andrés Bello (Viña del Mar, Chile). 
Lacan propone en su tesis De la psicosis paranoicas en sus relaciones con la personalidad (1932/2010), un concepto de paralelismo como resultado de una problematización de las relaciones entre el cerebro y las imágenes, relación que habría llevado a suponer que la personalidad podía ser "paralela" a los procesos neuráxicos. De manera explícita, su crítica se dirigirá al paralelismo psicofísico de Hypolitte Taine, así como también a la doctrina del automatismo mental representada por su maestro en psiquiatría Gaëtan Gatian de Clérambault. Las nociones implicadas en este paralelismo - también denominado como "psico-neurológico" — condujeron a sostener la idea de un déficit como base explicativa de las psicosis.

Por el contrario, Lacan intentará dar cuenta de la locura como un fenómeno del pensamiento, encontrando casos de psicosis paranoicas que no presentaban lesión cerebral. La manera de ilustrarlo será la presentación del caso Aimée y para justificar su propia versión del paralelismo, Spinoza será mencionado como la legítima doctrina al respecto. Veremos que en las líneas que preceden la referencia al filósofo, ha surgido una conexión, en un pie de página, con la biología de Jakob Von Uexküll (p. 307). A través de recursos tanto filosóficos como zoológicos, Lacan expondrá una concepción particular del paralelismo, la cual se encontrará en relación directa con el problema de la discordancia afectiva que distingue a las psicosis y que será explicada con una proposición, utilizada como epígrafe de su tesis, presente en la Ética (1980) de Spinoza. Surgirá así, la idea de que la personalidad es paralela al conjunto compuesto por el individuo y su medio, lo que para Lacan (1932/2010) tendrá un alcance que deberemos llegar a entender a través de su crítica al dualismo psicofisico, puesto que: "Esa concepción legítima del paralelismo es la única que permite [...] dar razón a la vez del conocimiento verdadero y del conocimiento delirante" (p. 307). 


\section{ARTIGOS}

\section{Elementos de discusión: el caso Aimée y la ausencia de déficit orgánico}

Puesto que mencionábamos la no detección de un déficit orgánico en la paranoia de Aimée, es importante señalar algunos elementos del caso. Sin indicios de daño neurológico, retraso en la inteligencia o de disposición congénita (pp. 157-160, 220), ha surgido en ella el delirio de que alguien quiere dañar a su hijo; aparecen así una serie de figuras femeninas persecutorias, llegando finalmente a una actriz a quien ataca utilizando un cuchillo. Las imágenes persecutorias habrían respondido, según Lacan, a un prototipo que sería el de la hermana mayor, a partir de la cual se habría forjado su propia imagen a modo de Ideal del yo. Al atacar entonces a la actriz, ataca su propia imagen (1932/2010, pp. 138-157, 237-238). El diagnóstico de Lacan es el de una psicosis paranoica (p. 186) con prevalencia de mecanismos autopunitivos (pp. 224-238).

Las variedades de la paranoia de autocastigo y la reivindicativa cumplirían con una fijación genética donde la personalidad se configura en sus aspectos de intencionalidad subjetiva y tensión social (p. 299). La intención característica en ambas no sería más que una pulsión agresiva, propia de la etapa libidinal en la que se produce la fijación y en donde las economías energéticas no se encuentran más que invertidas a consecuencia de contingencias históricas (p. 303). De ahí que Lacan pueda afirmar que: "[...] el delirio es el equivalente intencional de una pulsión agresiva insuficientemente socializada" (p. 304).

Pero antes de habernos presentado el caso Aimée, Lacan ya nos ofrecía como problema la suposición de un déficit orgánico como explicación de las psicosis. Intentando resaltar el concepto de tendencia concreta, enunciaba la diferencia jasperiana entre proceso y desarrollo. ${ }^{1}$ El concepto de proceso psíquico hace referencia a la aparición brusca y repentina de una tendencia que modifica por completo la personalidad, al contrario de los delirios que se configuran como un desarrollo de la misma. De este modo, la suposición de un proceso no solo implica el surgimiento de una intención exógena que configura una personalidad nueva - sometida también a las llamadas relaciones de comprensión - sino que reaviva el debate por el alcance de las lesiones orgánicas, las que habitualmente producen una desintegración mental

${ }^{1}$ Cuestión que revisa en detalle hacia el final del apartado 4 en De la psicosis paranoica en sus relaciones con la personalidad (1932/2010, pp. 94-135). 
(p. 128). Es por esto que Lacan retoma el problema de los posibles aportes a la investigación del factor orgánico bajo la crítica de lo que denomina como "la doctrina clásica del paralelismo psico-neurológico, remozada con el nombre de 'automatismo mental'" (p. 306).

\section{Contra Clérambault y a favor de la metamorfosis de las plantas}

Esta versión "remozada" del paralelismo psicofísico, no es otra que la de Clérambault. Si bien Lacan establece un recorrido erudito por la psiquiatría de la época (pp. 50-134) y en el cual rechazará las teorías constitucionalistas - díganse Sérieux y Capgras, Dromard, Clérambault, Dupré, Montassut, Genil-Perrin (pp. 59-69) — al mismo tiempo que rescatará ciertas nociones de la psiquiatría alemana - Kraepelin, Bleuler, Kretschmer (pp. 50-58, 69-74, 79-93) el blanco de su ataque seguirá siendo ante todo la doctrina del automatismo mental. Cabe señalar en conjunto que, al rechazar la noción de proceso inclinándose por el desarrollo, Lacan se distanciaba también de Jaspers pese a que utilizaba una diferencia propiamente jasperiana (proceso/desarrollo) y pese a la posible inspiración anti-paralelista que podía encontrarse en la fenomenología psiquiátrica introducida por el autor alemán (1993). La razón se debía a que el proceso — por mucho que fuera psíquico - seguía conteniendo en él restos de paralelismo psicofísico a través del aspecto incomprensible que se introducía como elemento nuevo en la personalidad, es decir, el llamado "fenómeno elemental" (Lacan, 1932/2010, pp. 197-198) equivalente de alguna forma, al automatismo.

De la psicosis paranoica... es una tesis que intenta distanciarse de cierta imagen representativa de lo que serían las relaciones entre el delirio y el pensamiento normal, conflicto donde Clérambault despliega los principios inherentes al paralelismo psico-neurológico clásico. En torno a este ejercicio de desprendimiento de las lecciones aprendidas del maestro, el papel jugado por la morfogénesis goethiana en el joven Lacan, a excepción de algunos autores (Arnoux, 1994; Baños Orellana, 2010, 2013), ha sido pocas veces mencionado. ${ }^{2}$ Sin embargo, esta nueva referencia se señala explícitamente

${ }^{2}$ Por esta misma razón seguiremos en este apartado las observaciones de Baños Orellana, condensadas principalmente en "La Novela de Lacan" (2013). 


\section{ARTIGOS}

en una nota al pie de página de la tesis a propósito de las "formas del pensamiento paranoico", las que serían las mismas tanto en el delirio como en la percepción:

Esta impresionante identidad estructural entre los fenómenos elementales del delirio y su organización general impone la referencia analógica al tipo de morfogénesis materializada por la planta. Esta imagen es seguramente más válida que la comparación con el anélido, que nos fuera inspirada, en una publicación anterior, por las aproximaciones aventuradas de una enseñanza completamente verbal (Lacan, 1932/2010, p. 270)

La anterior publicación mencionada por Lacan es un texto escrito por él un año atrás, titulado Estructura de las psicosis paranoicas (1931), lugar donde aún otorgaba valor a la comparación realizada por Clérambault en su enseñanza oral respecto de la interpretación delirante: "Estamos, como se ha dicho, ante "un anélido, no ante un vertebrado" (p. 7). Volviendo a 1932, notamos que el momento en el que surge el pie de página acerca de la morfogénesis es un párrafo donde Lacan (1932/2010) expone la necesidad de contar con una "estructura conceptual particular que se extiende a las psicosis paranoicas y las psicosis vecinas" (p. 270). El espíritu de una estructura así, era comentada por Goethe (1997) del siguiente modo en La metamorfosis de las plantas: "El mismo órgano que se expande en el tallo como hoja y toma las formas más diversas, se contrae luego en el cáliz, vuelve a expandirse en los pétalos, se contrae en los órganos reproductores, y se vuelve a expandir, por último, como fruto" (p. 31). En efecto, la planta no sería otra cosa más que hoja, la cual progresa o regresa.

El asunto en cuestión marca el alejamiento respecto del organicismo de Clérambault quien no podía sino conducir al pensamiento delirante a un registro exclusivamente evolutivo para demostrar su deficiencia, gesto que aseguraba la división entre las diversas clases de psicosis y de éstas respecto del pensamiento argumentativo normal, más parecido a la organización de un vertebrado. Si el automatismo mental definido por Clérambault era considerado como la base del delirio, estos fenómenos elementales respondían a desechos del pensamiento, producidos por un funcionamiento cerebral deficitario (Baños Orellana, 2010, p. 185). Así Clérambault (2009) consideraba como productos subconscientes a las Ideas Primitivas y al automatismo mental como: "[...] receptáculo de los mecanismos inferiores del pensamiento" (p. 108).

Por esta razón Lacan afirmaba que a propósito del estudio de las formas mentales de representación que el caso Aimée ofrecía como resultado, había 
que cuidarse de seguir las metáforas arquitectónicas que la neurología de la época defendía, puesto que hacían de la psicosis un déficit de los centros de control con la consecuente liberación - el llamado automatismo — de los centros inferiores $(1932 / 2010$, p. 261).

La generalización de la hoja a partir de Goethe, al situar en una misma estructura toda una diversidad clínica, permitía el abandono de la idea de déficit o de retraso evolutivo. ${ }^{3} \mathrm{He}$ aquí la importancia de que las plantas carezcan de sistema nervioso: otorgan una imagen adecuada para abandonar el canon de la referencia al cerebro como centro de operaciones subjetivo que gobierna al resto de las facultades organísmicas, idea que tiene la consecuencia de poner a todo aquello que parezca alejado del pensamiento llamado normal bajo el alero de la locura en tanto falla del sistema nervioso.

De esta manera vemos cumplirse lo que había sido en verdad la primera cita con la que Lacan rinde homenaje a la morfología goethiana: "Un mismo carácter estructural puede presentarse - y ahí está todo el estudio de la morfología - bajo aspectos muy diferentes" (1932/2010, p. 47). Con Aimée, se trata ahora de establecer similitudes que a primera vista parecen inexistentes y para lo cual, la metamorfosis de la planta presta un paradigma más acorde que el de los anélidos. Ya no se trata de jerarquías evolutivas, por el contrario, las transformaciones y pasos posibles son entendidos gracias a una única estructura que permite ubicar en ella fenómenos diversos. La morfogénesis goethiana es en definitiva una importante herramienta en la crítica del joven Lacan al paralelismo psicofísico.

\section{Contra Taine y con Bergson}

Uno de los momentos en que Lacan explicita su crítica al paralelismo se encuentra en un comentario a la doctrina de Hypolitte Taine. Ya en las primeras páginas de la tesis establece distancia cuando se interroga acerca del valor de las investigaciones psicógenas que mantienen la necesidad de estudiar la estructura de los fenómenos causados por lo orgánico. Al respecto mencionaba: "Por lo demás, apenas será necesario subrayar lo mucho que el

${ }^{3}$ Observemos en conjunto que Lacan obtuvo parte de su conocimiento de Goethe por la vía de los trabajos de Wilhem Troll, única referencia a las cuestiones morfológicas presente en la bibliografía de su tesis (Lacan, 1932/2010, p. 329). 


\section{ARTIGOS}

conjunto de estas consideraciones se aleja del falso paralelismo psicofísico según Taine" (p. 43). Este paralelismo que se caracteriza, en palabras de Lacan, por suponer que "toda representación es producida por una reacción neuronal no identificada" (p. 306). Dicha característica impediría postular una diferencia entre percepción y alucinación ya que la percepción sería concebida como una "[...] "alucinación verdadera", lo cual es la definición misma del milagro perpetuo" (p. 306). ¿Cómo concebir entonces el dominio de las imágenes? Para Taine (1904), hay una distancia entre sensación e imagen, donde ésta última sería exclusivamente una reproducción de la sensación, siempre más débil en intensidad y menos precisa (pp. 76-78). Así como el paralelismo psicofisológico de Hughlings Jackson impedía por sus "prejuicios" el estudio de los mecanismos conceptuales de las psicosis a través del lenguaje y sus integraciones funcionales (Lacan, 1932/2010, p. 261, n. 45), el "falso paralelismo psicofísico" de Taine (p. 43) impide ver el papel de la personalidad en estas. Este paralelismo arruina toda "objetividad" (p. 306), conglomerado de frases sueltas que creían "[...] sustituir los principios de objetividad por unas cuantas afirmaciones gratuitas acerca de su materialidad" (ídem.).

Con el fin de aportar a la cuestión de los determinantes orgánicos, Lacan plantea más bien que el cerebro, almacenando las impresiones del medio y de su propio cuerpo, registra todo aquello que sería del orden de un comportamiento diferido, es decir, una intención. Así, se configuran en él estructuras de comportamiento mas no imágenes. Éstas, por el contrario, no son almacenadas en ningún lado que no sea en "la sensación misma que les da toda su materia" (ídem.).

Las imágenes entonces no tendrían ningún paralelo fisiológico en la medida en que no serían algo diferente de las sensaciones mismas que les dan su materia. Es por esta razón que Lacan destaca la crítica emprendida por Henri Bergson en Materia y memoria (2006) a las localizaciones cerebrales de las imágenes, la que consiste básicamente en demostrar que el cerebro, por el hecho de ser materia - y por ende una cosa del mundo - es también una imagen. Lo único que de este modo podría almacenarse ahí serían una serie de movimientos asociados a determinados afectos, recuerdos o pensamientos, pero no el contenido de los mismos (pp. 27-93). El cerebro no es más que otra imagen-materia que responde a una imagen ciertamente privilegiada entre otras: la del cuerpo, el que consiste en un objeto (imagen) que mueve objetos que a su vez se definen como reflejo de las acciones posibles del cuerpo sobre éstos (pp. 38-39). 
En 1904, Bergson denunciaba el paralogismo inherente a la hipótesis del paralelismo psicofísico, no solo al señalar que consiste en una idea cuyo origen es indudablemente metafísico (2012, p. 204), sino al demostrar que en el momento mismo en que se enuncia, dos perspectivas opuestas entre sí se reúnen ya sea en una ambigüedad insalvable o en un paso irreflexivo entre ambas; estos sistemas de notación serían para Bergson el idealismo y el realismo (pp. 205-218). Este problema argumentativo es bastante similar a lo que Lacan observa en su seminario 3 a propósito de la causalidad psíquica: cuanto más organicista se sea, más psicogenético se es y la razón de esto se debe a que comparten sin saberlo la referencia metafísica al alma, supuesta entidad unificante de lo mental (2012, p. 56). Una observación de este tipo ya se encontraba en 1932, cuando respecto a las posibles acusaciones de caer en la psicología, Lacan (1932/2010) demostraba que en verdad es el organicista el que sin saberlo, cae en sus propias acusaciones al tratar a los fenómenos de las psicosis como si tuvieran existencia independiente a la conciencia y la conducta del sujeto, quien los registra como objetos en sí: "Y si a tales delitos les supone el cuerpo de alguna lesión (puramente mítica, por cierto), sin duda este doctrinario creerá haber demostrado así la inanidad 504 de la "psicología", pero de hecho está erigiendo en ídolos los conceptos de la psicología" (p. 282).

En su conferencia dictada en 1912 titulada "El alma y el cuerpo" (2006), Bergson afirmaba que el "alma", el "espíritu" o el "yo", desbordaban en cada punto a la determinación espacial del cuerpo (pp. 274-275). Le parecía que la observación directa del cerebro solo podría ofrecernos un cúmulo de gestos o movimientos que no nos permitirían entender lo que en verdad ocurre cuando estos se presentan, a la manera de espectadores de una obra de teatro donde solo vemos los movimientos de los actores pero no sabemos nada del contenido de la pieza (p. 284). En efecto, es con exactitud lo que Lacan (1932/2010) parafrasea a propósito de las imágenes y su localización anteriormente mencionado (p. 306).

A propósito del ritmo y el movimiento del pensamiento, Bergson afirma que la fluidez de las palabras debería poder expresar este ritmo, el cual corresponde a la exteriorización de la acción del pensamiento, movimientos preformados en el cerebro (p. 288); luego, el cerebro se encargaría de darle el anclaje material al pensamiento (pp. 288-289).

Ante la dificultad de proponer algo que reemplace al paralelismo, Bergson decide abordar aquellos fenómenos en los que se ha querido comprobar la doctrina: las enfermedades de la memoria (p. 291). 


\section{ARTIGOS}

Específicamente, el estudio de las afasias y sus manifestaciones indicarían en verdad que no es posible concebir que los recuerdos estén impresos en el cerebro, sino que más bien, este se encuentra a cargo de recordar el recuerdo y no de conservarlo (p. 293). La conclusión es entonces que si los recuerdos no son algo material, la pregunta por el lugar donde se localizan queda desautorizada: para Bergson están sencillamente en el espíritu (p. 295). Siendo así, la conciencia se revela inseparable de la memoria (p. 296), puesto que el presente siempre se vuelve pasado siguiendo el ejemplo de las sílabas que desfilan en una palabra, o de las palabras desplegadas en una frase (ídem.).

Si bien el filósofo supera la idea de que el pensamiento resulte afectado por la falla en el cerebro, al explicarse la diversidad de cuadros posibles de una enfermedad por pérdida en el espíritu de un ajuste a lo real (situación o vida) ocasionada por la lesión cerebral (pp. 289, 290, 293, 297), parece encontrarse acá una perspectiva que no deja de explicar la locura por falla orgánica.

\section{Con la zoología de Von Uexküll}

Luego de criticar a la tradición influenciada por Taine, aunque insistiendo en el intento por colaborar con los determinantes orgánicos, la mención a Bergson tomará un relevo a primera vista inesperado. El próximo pie de página quedará a cuenta de un zoólogo. Así, la referencia a Jakob von Uexküll surgirá a título de doctrina plausible de solucionar los asuntos implicados en el paralelismo. Se trata de un gesto que instaura al mismo tiempo una suerte de continuidad entre lo que Lacan estima como una correcta consideración de las imágenes en tanto no almacenadas por el cerebro y aquel paralelismo que distinguirá como el verdadero y el más fructífero para las propuestas que viene presentando: el de Spinoza. A través de estos recursos, Lacan (1932/2010) puede afirmar que la personalidad sería paralela, no al cerebro ni sus "procesos neuráxicos" (p. 307) sino "[...] a la totalidad constituida por el individuo y por su medio propio" (p. 307).

Habiendo expuesto un posible aporte a las determinaciones orgánicas de las psicosis, Lacan puede demostrar que, si el cerebro solo almacena movimientos corporales, traducidos en intenciones que configuran estructuras de comportamiento en conjunto con las impresiones del medio, la personalidad solo puede ser paralela a este medio constituido por imágenes, 
las que, en el caso del humano, se organizan como un medio social. El pie de página donde Lacan menciona a von Uexküll resulta así clarificador:

Una escuela de biología de una importancia capital ha elaborado en su pleno valor esta noción del medio propio de un ser vivo dado; el medio, según es definido por esta doctrina, aparece de tal manera ligado a la organización específica del individuo, que llega a hacer de él, en cierto modo, una parte suya. Cf. Los trabajos fundamentales de J. von Uexküll, sobre todo Umwelt und Innenwelt der Tiere, Berlín, 1909. (1932/2010, p. 307, n. 21)

Nos quedaría entender la especificidad de ese medio social en tanto humano, medio que se constituye por imágenes al igual que en el animal.

A diferencia de una concepción mecanicista del funcionamiento animal, von Uexküll (2016) proponía ante todo que la unidad individual es en verdad un sujeto "[...] que vive en su propio mundo, cuyo centro consiste en él mismo. Por lo tanto, no puede ser comparado con una máquina, sino tan solo con el maquinista que conduce la máquina" (p. 39). Así, se representaba el funcionamiento de los sucesos biológicos como la presencia de hilos que unen elementos heterogéneos, indispensables para que transcurra la vida de los seres; a propósito del descubrimiento de Newton dirá: "El gran físico tuvo ante sus ojos las relaciones invisibles de la naturaleza como verdaderos fenómenos" (2014, p. 140).

La vida establece, según esta concepción, relaciones impensadas, las cuales hacen de los animales seres cuya propiedad característica se define por el lazo invisible con algún elemento determinado del entorno, el que pasa a constituirse, por este motivo, en propiedad de su mundo. Pero no hay que ver en estas relaciones una pura situación de adaptación. Von Uexküll es enfático en su crítica a los planteamientos darwinianos. Por el contrario, no habrían animales mejor o peor adaptados, sino que cada uno de ellos estaría siempre y en rigor, perfectamente ajustado al "mundo circundante" (Umwelt). En reemplazo entonces de la adaptación (Anspassung-Adaptation) tenemos el ajustamiento (Einspassung). Cada organismo interactúa con una imagen determinada al interior de un objeto, la cual tiene una significación que desencadena una acción. Este movimiento es entendido por von Uexküll a la manera de una relación musical: se trata de melodías - con sus componentes temporales y espaciales (pp. 58-74) - que pueden encontrar contrapuntos en aquellos objetos que pasan a ser considerados como "portadores de significación" (Heredia en von Uexküll, p. 23) o "portadores 


\section{ARTIGOS}

de características" (von Uexküll, p. 87). Habría entonces una diferencia entre el el Umwelt (el mudo circundante) y el "entorno" (Umbegung). En el umbegung existe una polifonía por la presencia simultánea de múltiples mundos circundantes, es decir, por numerosas melodías que en su conjunto constituyen a la naturaleza como una inmensa composición sinfónica.

La diferencia establecida entre entorno y mundo circundante, permite a su vez distinguir entre objeto y portador de significación, con la consecuencia inevitable de que el organismo vivo no se relaciona jamás con objetos en tanto tales, sino tan solo con las partes de éste que tienen una significación pre-establecida para el organismo que interactúa con ellas (pp. 89-90). Es por la presencia de estas imágenes o signos perceptuales (Merkmal) que el objeto será, no uno en su totalidad, sino como hemos mencionado, un "portador de significaciones". Ante un objeto que no porte estas características el animal permanecerá indiferente. Es por esta razón que Lacan define a la relación que se produce al interior del Umwelt como una donde el "objeto" parece ser una parte del mismo organismo, casi como si éste portara de antemano su objeto. Esta relación significativa es la que constituye un "círculo funcional" (p. 88), compuesto por el Innenwelt (mundo interno) y el Umwelt.

Por otra parte, que las imágenes no se ubiquen o almacenen en el cerebro es también una indicación de von Uexküll. Es lo que ocurre tanto con las sensaciones (p. 44), como con la memoria, entendida como un órgano anímico que conserva reglas y las dispone según el uso: "Dado que las reglas dominan tanto las sensaciones de lugar como las de tiempo, el órgano no es en sí mismo ni espacial ni temporal. También las imágenes son conservadas en la memoria" (p. 78). La indicación se aplica por igual respecto de la configuración de sus esquemas, cuestión que amplifica la crítica al paralelismo (p. 154).

Pero hay un tipo particular de imagen que parecería contradecir la funcionalidad. Se trata de la "imagen de búsqueda". Es lo que ocurre con el sapo que al comer una lombriz después de un prolongado ayuno: "[...] inmediatamente se abalanzará sobre un fósforo que tenga cierta semejanza formal con la lombriz. Esto nos lleva a creer que la lombriz recientemente ingerida funciona como una imagen de búsqueda [...]" (2016, p. 135).

Se nos presenta aquí una condición de relevancia: en efecto, la imagen de búsqueda se constituye en el animal a partir de una imagen perceptual original que tiene el potencial de transformarse en una imagen efectual, es decir, en una que implicará una acción posible sobre ésta. La imagen de búsqueda surge desde el esquema habitual de percepción (p. 133), salvo 
que, por el ímpetu que produce la determinación de lo buscado, esta imagen anula la imagen perceptual. Podríamos suponer que en el caso del hombre, la imagen de búsqueda es más bien la imagen habitual, que ésta no es solo el producto de alguna alucinación que indique que algo anda mal en el nivel cerebral; la imagen de búsqueda parece un buen ejemplo del medio humano en tanto podemos afirmar que somos constantemente "engañados" en nuestra relación a las imágenes y que éstas responden a una imagen que constituye finalmente, tal y como Lacan quiere demostrarlo con Aimée, nada más que la imagen de sí mismo, o más correctamente, la imagen exterior a partir de la cual se ha constituido el yo.

De este modo podríamos sostener que en el humano, el "error" es lo habitual. La imagen en él es siempre imagen de búsqueda, puesto que el objeto remite a esa Urbild constituyente del yo. No por tratarse de una psicosis, Aimée dejaría de mostrarnos la configuración general del yo humano; de lo contrario, los ataques de Lacan al paralelismo y su distancia respecto al organicismo difícilmente podrían ser afirmados, puesto que su caso solo habría servido para plantear que en ella falla algo por un déficit en la captación de la imagen. Sin embargo, lo que no deja de resultar cierto, es que algo la distingue respecto de una mayoría que habita un determinado medio social, razón por la cual se constituye el delirio y sobreviene el acto del ataque a la actriz; pero esto no es resultado de un error, es resultado de una negación en sentido freudiano (Lacan, 1932/2010, p. 229) que tiende a desconocer las condiciones bajo las cuales el yo será ese otro cuya imagen resulta prototípica.

Esta perspectiva nos ofrece la posibilidad de entender los diversos modos en que se relacionan el conjunto de las funciones de un organismo con sus imágenes significativas. Tratándose del caso Aimée, que expresa de forma particular la instauración propia del medio social humano, podemos deducir que Lacan está intentando, con ayuda de la zoología, dar cuenta al mismo tiempo, de una condición humana en general — es decir, a qué es paralela la personalidad - y de una especificidad que manifiesta por otras vías esa condición (la psicosis paranoica de autocastigo). La personalidad misma puede considerarse un Umwelt en el cual se presentan imágenes significativas que pueden variar de tal manera que algunas se constituyen como compartidas por una mayoría en el nivel del medio social y otras parecen exhibirse de manera discordante a ésta.

Sin embargo, no podríamos dejar de observar que, si bien se presenta esa discordancia, no por ello la conducta o el acto de Aimée deja de 


\section{ARTIGOS}

estar en concordancia con la imagen que la mueve. Si bien el "ciclo de comportamiento" (p. 282) delirante parece no coincidir con el asentimiento social — quitándole objetividad al delirio —, al responder al paralelismo según Lacan y a las relaciones de comprensión presentes en la historia del sujeto, el Umwelt del delirante se constituye exactamente del mismo modo que cualquier otro Umwelt; su medio social es el mismo, salvo que la reacción a los signos a los cuales se ajusta, no se expresa por las mismas vías en que lo hacen cierto número de individuos, aun cuando, observemos, comparte el mismo lenguaje que éstos (p. 307). Estos aspectos representan para Lacan la posibilidad de volver inteligibles las psicosis de un modo no deficitario.

La diferencia propiamente lacaniana que surgiría respecto a von Uexküll, es que la imagen a la cual reaccionaría el humano ya no depende ni del objeto ni del sujeto; o más bien, depende del sujeto en la misma medida en que éste desconoce esa imagen que le resulta significativa y que lo constituye originalmente. Con Lacan no ponemos el centro en el maquinista, sino que comienza a instalarse la idea de que la imagen es constituyente, lo que no significa un retorno al énfasis en el objeto. El hombre desconoce que la imagen de los objetos que capturan su atención libidinal son reflejos de él mismo, por lo que el mundo parece ofrecer un espejo para ese ser prematuro que es el hombre. El agregado de "social" para el concepto de medio es la manera en que Lacan destaca el punto específicamente discontinuo que se produce en la continuidad animal-hombre.

Si la crítica al paralelismo psico-físico se realiza en el joven Lacan (1932/2010) poniendo en relación a von Uexküll con Spinoza, ¿cómo entender lo que sin embargo se sigue definiendo como una discordancia delirante en Aimée respecto al medio? Para esto, habría que profundizar en el paralelismo spinozista, "primera expresión" (p. 307) de dicha concepción y que permitirá a Lacan exponer su propio paralelismo "como la única digna de tal nombre" (p. 307).

\section{Con Spinoza: paralelismo e igualdad}

Las nociones de von Uexküll permiten definir el tipo de relación que existiría entre el medio animal y el medio social humano. Poner en conjunto esta biología con el paralelismo spinoziano tiene la consecuencia de explicar en un solo plano el conocimiento verdadero y el conocimiento 
delirante (Lacan, 1932/2010, p. 307). El caso de paranoia de autocastigo en Aimée demostraría el uso que Lacan hace de Spinoza a lo largo de su tesis, principalmente a través de dos menciones que armonizan entre sí.

La primera referencia al filósofo aparece en el epígrafe de su tesis, lo que corresponde a la proposición LVII de la parte III de la Ética: "Un afecto cualquiera de un individuo difiere del afecto de otro, tanto cuanto difiere la esencia del uno de la esencia del otro" (1980, p. 167). Hacia el final de la revisión del caso Aimée es nuevamente presentada como constatación de congruencia entre sus ideas y los principios de la doctrina spinozista (Lacan, 1932/2010, p. 312).

La segunda referencia es la que hemos venido mencionando a propósito del paralelismo (p. 307). ¿Cómo se conectan el concepto de discordancia presente en la proposición LVII y la doctrina del paralelismo? Si tomamos primero el camino del paralelismo, es necesario mencionar lo siguiente: se sabe y se ha dicho (Deleuze, 1999, 2006, 2008; Jaquet, 2004) que este concepto no es de Spinoza y que, pese a esto, ha quedado asociado a dicha doctrina. Como sea, hay acuerdo en que, incluso cuando el término se sigue utilizando, el sentido de lo que así se designa es otro que con respecto 510 al uso más tradicional. Es por esto que si bien Lacan usa el término de "paralelismo" para encontrar en Spinoza una importante justificación de su propio pensamiento, tiene claridad en que no se trata de simples registros paralelos que, tal como señalaba Bergson (2006), hacían del cerebro la sede de todo lo que ocurriría en el espíritu, no siendo la conciencia nada más que una fosforescencia sobreañadida a los movimientos que acontecen en dicho órgano (pp. 275-277). Es por esto que necesitamos revisar el alcance de este paralelismo "lacaniano-spinozista". Como veremos, Lacan parece entender, aun cuando utilice la palabra "paralelismo", que en Spinoza se trataría más bien de una "igualdad" (Jaquet, 2004, p. 15).

La llamada doctrina del paralelismo en Spinoza se encuentra expresada en la proposición VII del libro II de la Ética (op. cit.), donde se nos dice que "el orden y conexión de las ideas es el mismo que el orden y conexión de las cosas" (p. 75). Los problemas comienzan desde el momento en que se intenta dar cuenta del tipo de relación que se produce entre ambos órdenes y sus respectivas conexiones. En este punto específico, la lectura deleuziana sobre Spinoza nos ayudará retroactivamente para darle un mayor énfasis a los planteamientos de Lacan.

En Spinoza y el problema de la expresión, Deleuze (1999) distingue tres versiones posibles: un paralelismo de orden, otro de conexión y finalmente 


\section{ARTIGOS}

uno ontológico, que sería el que mejor demostraría esta doctrina. A partir de las definiciones de sustancia, atributo y modo Deleuze sintetiza afirmando: "Porque esos atributos son todos iguales, hay identidad de conexión entre esos modos que difieren por el atributo. Porque esos atributos constituyen una sola y misma substancia, esos modos que difieren por el atributo forman una sola y misma modificación" (p. 104). En su curso sobre Spinoza define al paralelismo ontológico como: "[...] la misma cosa, la misma modificación produciéndose en el atributo pensamiento según el modo de un espíritu, y en el atributo extensión según el modo de un cuerpo" (2008, p. 87). Los modos son en definitiva los entes que, implicando atributos, son envueltos por la sustancia como expresión de la misma. Si el ser se dice del ente, entonces todo cuerpo o individuo es un modo, una manera de ser (p. 45). Cualquier choque o incompatibilidad entre ellos, lo es en virtud de una incompatibilidad de las relaciones de velocidad o lentitud que los definen (p. 46).

Ahora bien, los entes no son seres pero poseen la consistencia de una relación (p. 160). Son relaciones y constituyen a la vez relaciones con otros entes o modos. La potencia o el grado de potencia definen a este ente relacional (Deleuze, 2006, p. 38), describiendo la efectuación de las relaciones de estas esencias singulares y a lo que corresponde siempre un poder de afección (p. 38). El paralelismo ontológico, nos permite afirmar que no solo existe el conjunto de relaciones constitutivas de los modos, sino también las relaciones entre ellos; nos ofrece la opción de pensar una relación donde la diferencia puede expresar una única sustancia o donde las esencias pueden diferir al mismo tiempo que expresan al mismo ser.

Nuevamente en su curso sobre Spinoza, Deleuze (2008) pone acento no sobre la tendencia o el esfuerzo, sino sobre la "perseverancia" (pp. 101, 140, 141). Para nosotros es un acento ventajoso puesto que dicha perseverancia solo podría ser entendida como la manera en que un cuerpo efectúa las relaciones que le convienen. Se persevera entonces en la medida en que no se deja de componer y deshacer relaciones según el conjunto de relaciones constitutivas de un cuerpo (p. 140). Estas relaciones, que incluirán los afectos y afecciones, son la esencia por medio de la cual un cuerpo podrá existir y sin la cual, no podría ser (Spinoza, 1980, pp. 69, 125, 131-132, 166-168, 170).

Llegamos así a la proposición LVII, de la parte III referida por Lacan. Esta tercera parte de la Ética — dedicada a los afectos - resulta para Chantal Jaquet (2004) la mejor demostración de la igualdad entre cuerpo y espíritu (pp. 20-21). Por su parte, Deleuze (2006) comenta que el poder de afección de la "esencia singular", es permanentemente satisfecho por las afecciones 
mismas (p. 38). De aquí se desprenden las acciones y pasiones; la primera proviene de la esencia del individuo y la segunda es derivada de otra cosa proveniente del exterior, ya sean tristes o alegres (p. 38).

El afecto será entonces lo que efectúa a cada instante la potencia, la cual no puede existir por fuera de los afectos que la completan (Deleuze, 2008, p. 94). Las afecciones por su parte, conocen dos niveles: uno de la sustancia (2006, p. 62) y otro, el de los modos, indicando estas últimas los estados de los cuerpos al entrar en relaciones con otros cuerpos, los cuales son considerados en su valor de imágenes. Para Spinoza (1980) entonces: "[...] cuando el alma considere los cuerpos de esa manera, diremos que los "imagina"” (pp. 91-92). Las afecciones del cuerpo son en definitiva imágenes de los cuerpos exteriores que lo afectan.

Si los afectos son la cualidad de estas variaciones modales ya sea que se trate de pasiones alegres o tristes, habría que agregar un tercer afecto fundamental: el deseo, definido por Spinoza como un apetito consciente (y por lo tanto referido a los hombres (p. 132)), pero también como "[...] la esencia misma del hombre en cuanto es concebida como determinada a hacer algo en virtud de una afección cualquiera que se da en ella" (p. 170); siendo 512 así, el deseo prescinde de la obligatoriedad de consciencia puesto que sigue siendo el mismo se esté o no al tanto de él (p. 170).

En definitiva, los afectos de alegría o tristeza son, según Deleuze (2006), pasos de perfección que puede ser o más grande o más pequeña (pp. 63-64). Aunque un afecto sea causado por una imagen o idea, éste no es reducible a ella "[...] es de una naturaleza distinta, puramente transitivo y no indicativo o representativo, y se experimenta en una duración vivida que engloba la diferencia entre dos estados" (p. 63). Al respecto, encontramos en la Ética dos explicaciones de los afectos, una en la definición III de la tercera parte (op. cit., p. 124) y la otra como definición general hacia el final de la misma tercera parte (p. 182).

Jaquet (2004) señala una divergencia entre ambas definiciones, la cual estaría determinada por la relevancia que Spinoza habría dado a la modalidad del espíritu, aunque sin por eso, descartar al cuerpo (pp. 72-82). La clave de esta variación estaría tanto en el sentido de la palabra generalis empleada por Spinoza (1980), como en la definición XLVIII dada a los afectos (p. 182), justo antes de la definición general. Y es que, el generalis remitiría a la importancia de una definición en verdad genérica de los afectos, y en última instancia, la que sería propia del segundo género de conocimiento, es decir, en aquel que es determinado por la razón (Jacquet, 2004, pp. 78, 79, 


\section{ARTIGOS}

82); el motivo es que Spinoza (1980), tal como lo demuestra la definición XLVIII, ha puesto su atención sobre el espíritu debido a que pretende señalar de qué manera éste podría tener un poder sobre los afectos pasivos. Es por esto que define genéricamente al afecto como una idea confusa, puesto que en el obrar o la acción, el cuerpo es involucrado como causa adecuada que genera una idea clara y distinta que se explica por ella misma (p. 124), al contrario del padecer, definido "[...] cuando en nosotros ocurre algo, o de nuestra naturaleza se sigue algo, de lo que no somos sino causa parcial" (p. 124). En efecto, ambas definiciones - la III y la general - parecen centrarse exclusivamente en las pasiones (padecer) antes que en las acciones (obrar); el proyecto de la "Ética" radicaría así en enseñar las vías que le permitan al espíritu sobreponerse a las pasiones (Jaquet, 2004, p. 77). Pero hemos señalado que esto no se realiza sin contemplar al cuerpo, no solo porque sea necesario involucrarlo en tanto que padece (p. 77), sino porque los afectos, puesto que comprueban una igualdad, nunca dejan de involucrar al cuerpo. Dando un paso más allá, observamos que la definición III, pese a que el aumento o la disminución de potencia parecen hablarnos solo de las pasiones, ya involucra en ella a los afectos activos en tanto potencia pura de acción y por ende, como alegría activa cuya potencia es plenamente aumentada, lo que en términos de Spinoza corresponde a la beatitud (pp. 249-279).

Con estas disquisiciones, podemos empezar a descifrar el sentido en que Lacan utiliza la propuesta spinozista. En principio, le permite subrayar cómo la potencia afectiva de un cuerpo, al estar siempre efectuada, demuestra que la esencia puede afectarse de diversas maneras en relación a otras y en consideración de las relaciones que puede establecer. Sean pasiones o acciones, los cuerpos difieren por su esencia, la cual no es más que grado, parte o potencia que varía según los afectos de los que son capaces, aunque todos ellos son iguales en tanto modos de la substancia. Observamos así que existe correspondencia entre una composición de relaciones que podemos llamar "intra" individual y otra a la que llamaremos "inter" individual. Las afecciones y los afectos comprueban en definitiva, el "paralelismo" o la igualdad, al mismo tiempo que incluyen en ellos y sus relaciones la diferencia entre esencias y la discordancia afectiva.

Por otra parte, si Spinoza intenta con los afectos una clasificación que otorgue una medida común "[...] entre los diversos individuos a fin de poderlos comparar" (p. 78), entonces obtenemos una definición algo más precisa de lo que se trata en Lacan: encontrar un criterio de diferenciación al 
interior de una medida común. Así, tanto personalidad normal como psicosis paranoicas son iguales bajo el hecho de ser sencillamente fenómenos de personalidad. Es por esto que la zoología puede ser invocada aquí, ya que el Umwelt incluye en él a los cuerpos que, en tanto imágenes, pueden afectar la naturaleza o esencia de otro cuerpo o individuo, el cual se define a su vez como conjunto de cuerpo y medio. Los animales podrán determinadas cosas, los humanos podrán otras según sus esencias. Podríamos decir que en Lacan, con la ayuda de Spinoza y al contrario de Descartes, tanto la locura como el animal constituyen casos fundamentales para entender la esencia de la razón humana. La prueba la podemos encontrar en el escolio de la misma proposición LVII (1980, pp. 167-168), la cual es demostrada con la libido o lujuria del caballo: libido igual que la humana, pero diferente en cuanto a lo que pueden afectivamente.

Aimée entonces está en discordancia con la potencia afectiva de los cuerpos que constituyen personalidades relativamente normales, pero enseña mejor la ley general de que una personalidad se define como paralela a la totalidad individuo-medio. En última instancia, habría que suponer que Aimée actúa en concordancia a la totalidad de las relaciones entre su cuerpo y el conjunto de imágenes que la constituyen, siendo estas iguales a su personalidad. Inesperadamente, la referencia al comportamiento animal resulta de ayuda para extraer estas conclusiones. El Umwelt es el concepto por el cual tenemos un criterio común y diferenciador a la vez entre las psicosis paranoicas y la personalidad normal. Habría entonces que suponer una igualdad que diferencia por variación gradual, no solo a la personalidad con las psicosis, sino al hombre con el animal.

\section{Conclusiones: el paralelismo lacaniano}

En definitiva, la relación Spinoza-von Uexküll habilita una lectura posible del lazo que a su vez se establece en Lacan entre su "paralelismo" - advertido de la igualdad spinozista - y la proposición LVII, III de la "Ética". Esto mismo es lo que explica que nos haya interesado más la tercera formulación del "paralelismo" que Deleuze (1999) considera como ontológica: “[...] los modos de atributos diferentes no sólo tienen el mismo orden y la misma conexión, sino el mismo ser; son las mismas cosas que se distinguen solamente por el atributo del que engloban el concepto" (p. 103). 


\section{ARTIGOS}

De lo que se trata en esta conjunción referencial llevada a cabo por Lacan, es de que la esencia constituye el despliegue de un deseo a partir de las variaciones que la definen como potencia afectiva, de modo que diferirá con otra en virtud de este criterio. Dicho de otra manera, lo que puede una psicosis, no lo puede una personalidad normal - o al menos, no lo sabe de antemano - y lo que puede ésta no lo puede aquella - o al menos, tampoco lo sabe de antemano; sin embargo, ambas tienen una base común, ambas son incluso lo mismo en concordancia con la igualdad, lo cual es demostrado con mayor énfasis por la psicosis paranoica.

Si bien explícitamente Lacan (1932/2010) está destacando las diferencias o discordancias (p. 312), es necesario alcanzar un nivel tácito donde se establecen las igualdades o "paralelos", o a la inversa, descifrando la igualdad, habría que poder captar el factor que produce diferencia y en qué nivel lo hace; es a partir de este punto que podemos entender la discordancia en el sentido lacaniano. Y es que, al tratarse de una discordancia que se produce en relación a los cuerpos exteriores, los términos ontológicos expuestos a partir de Spinoza nos permiten entenderla como variaciones de los modos entre sí, los que finalmente remiten a la substancia única.

Reafirmar la constatación de que la discordancia no es un asunto exclusivamente intra-individual, sino que ante todo, inter-individual, implica poner en primer plano la cuestión de la inteligibilidad del delirio, o en otros términos, definir lo que hace que en ciertos casos la personalidad tome las vías de la paranoia y en otros casos parezca normal. La discordancia, tal y como la propone Lacan, será tanto mayor mientras menos relaciones puedan componerse entre dos esencias, entregándonos la medida para diferenciar una personalidad normal de una psicosis paranoica, pero siempre considerando que, en tanto esencias y en virtud del "paralelismo" o la igualdad, estas son solo expresiones de una misma substancia. De este modo, y en conjunto con las consideraciones de Jaquet y su puesta en primer plano del concepto de igualdad, podemos decir que los elementos que entran en relación bajo ese concepto, no tienen, en rigor, relación; o al revés, no tienen relación porque son iguales, lo que explica la divergencia entre cuerpo y espíritu así como la diferencia o discrepancia entre las esencias, individuos o sencillamente, cuerpos. Esta no relación es lo que Lacan (1975-1976/2001) llegará a mencionar cuando, transcurridos más de treinta años de escrita la tesis y en ocasión de su publicación, afirme que: "[...] la psicosis paranoica y la personalidad como tal no tienen relaciones, simplemente por esto: es porque eso es lo mismo" (p. 10). 
En efecto el concepto de Paralelo parece significar relaciones de semejanzas, parecidos, equivalencias entre cosas. Por el contrario, la Igualdad anula las semejanzas, tanto de analogías como de homologías para dar paso a la divergencia de las modalidades, cuestión que conviene a Lacan para establecer una inteligibilidad de los delirios y dar razón simultánea al conocimiento verdadero y al delirante. Por lo tanto, cuando Lacan dice que la personalidad es "paralela" a..., de lo que se trata es de la igualdad del cuerpo (individuo) con las ideas o imágenes del espíritu (medio). El paralelo lacaniano, leído con la igualdad, demuestra que lo que ocurra en el individuo y su medio, ocurrirá en la personalidad; lo que acontece en el plano de las imágenes y sus percepciones sobreviene en el individuo-cuerpo según sus movimientos o reposos, acciones o pasiones, actividad o pasividad, y eso, ocurrirá por igual en todo ente, en la medida en que no es más que una modalidad del ser. Obtenemos así una definición común tanto para la personalidad como para la paranoia; pero ésta última, puesta en referencia a la potencia afectiva, podrá ser definida en virtud de su diferencia o discrepancia con otras esencias.

\section{Referencias}

Arnoux, D. (1994). La ruptura entre Jacques Lacan y Gaëtan Gatian de Clérambault. En Litoral 16, Antecedentes lacanianos (pp. 45-80). Córdoba, Argentina: E.D.E.L.P. Baños Orellana, J. (2010). Las novelas que nos contamos de Lacan. En O. Acha, \& M. Vallejo (Eds.), Inconsciente e historia después de Freud (pp. 167-186). Buenos Aires, Argentina: Prometeo Libros.

Baños Orellana, J. (2013). La novela de Lacan. Buenos Aires, Argentina: El cuenco de plata.

Bergson, H. (2006). Materia y memoria. Buenos Aires, Argentina: Cactus.

Bergson, H. (2006). El alma y el cuerpo. En Materia y memoria (pp. 273-299). Buenos Aires, Argentina: Cactus.

Bergson, H. (2012). El cerebro y el pensamiento: una ilusión filosófica. En La energía espiritual (pp. 203-221). Buenos Aires, Argentina: Cactus.

Clérambault, G, (2009). Automatismo mental: paranoia. Buenos Aires, Argentina: Polemos.

Deleuze, G. (2008). En medio de Spinoza. Buenos Aires, Argentina: Cactus.

Deleuze, G. (2006). Spinoza: filosofía práctica. Buenos Aires, Argentina: Tusquets Editores S.A. 


\section{ARTIGOS}

Deleuze, G. (1999). Spinoza y el problema de la expresión. Barcelona, Espanha: Muchnik Editores S.A.

Goethe, W. (1997). La metamorfosis de las plantas. En Teoría de la naturaleza, Madrid, Espanha: Tecnos

Jaquet, Ch. (2004). L'unité du corps et de l'esprit. Affects, actions et passions chez Spinoza. Paris, França: Quadrige/PUF (Presses Universitaires de France).

Jaspers, K. (1993). Psicopatología general. México, México: Fondo de Cultura Económica.

Lacan, J. ([1931]/s.f.). Estructura de las psicosis paranoicas. (Juan Bauzá, tradución y presentación). Paris.

Lacan, J. (2001). El sinthome, seminario 23, 1975-1976, clase del 16 de Diciembre de 1975. Establecimiento del texto, traducción y notas Ricardo Rodríguez Ponte, para circulación interna de la Escuela Freudiana de Buenos Aires. (Trabajo original publicado en 1975-1976).

Lacan, J. (2008). Acerca de la causalidad psíquica. En Escritos 1. (pp. 151-190). Buenos Aires, Argentina: Siglo XXI. (Trabajo original publicado en 1946).

Lacan, J. (2010). De la psicosis paranoica en sus relaciones con la personalidad. México, México: Siglo XXI. (Trabajo original publicado en 1932).

Lacan, J. (2012). Las Psicosis. En El seminario. Libro 3. Buenos Aires, Argentina: Paidós. (Trabajo original publicado en 1955-1956).

Spinoza, B. (1980). Ética, demostrada según el orden geométrico. Introducción, traducción y notas de Vidal Peña. Madrid, Espanha: Ediciones Orbis S.A.

Taine, H. (1904). La inteligencia. Madrid, Espanha: Daniel Jorro.

von Uexküll, J. (2016). Andanzas por los mundos circundantes de los animales y los hombres. Buenos Aires, Argentina: Cactus.

von Uexküll, J. (2014). Cartas biológicas a una dama. Buenos Aires, Argentina: Cactus.

\section{Resumos}

(A crítica do jovem Lacan ao paralelismo psicofísico em "Da psicose paranoica em suas relações com a personalidade")

Em sua tese de 1932 intitulada "Da psicose paranoica em suas relações com a personalidade", Jacques Lacan empreende uma crítica, dispersa em vários lugares dela, ao paralelismo psicofísico defendido pela tradição psiquiátrica. Nesse contexto, e como chave para explicar tanto as psicoses paranoicas quanto a paranoia 
autopunitiva do caso Aimée, o jovem psiquiatra apresentará sua própria versão de paralelismo, baseada em dois autores: Jakob Von Uexküll e Baruch Spinoza. Procuraremos destacar essa jornada, bem como as consequências de um paralelismo propriamente lacaniano.

Palavras chave: Paralelismo, psicose, Umwelt, discordância

(Young Lacan's criticism of the psychophysical parallelism in "Of Paranoiac Psychosis in its relations with personality")

In his thesis of 1932 entitled "De la psychose paranoïaque dans ses rapports avec la personnalite" (Paranoid psychosis and its relation to the personality), Jacques Lacan criticizes, in a scattered manner throughout his work, the psychophysical parallelism supported by psychiatric tradition. In this context and as a key to explain both the paranoid psychoses and the self-punishing paranoia of Aimée's case, the young psychiatrist presents his own version of parallelism based on two authors: Jakob Von Uexküll and Baruch Spinoza. We aim to highlight this endeavor and the consequences of Lacan's own parallelism.

Key words: Parallelism, psychosis, Umwelt [environment], discordance

(La critique du jeune Lacan concernant le parallélisme psychophysique dans «La psychose paranoïde dans ses relations avec la personnalité»)

Dans sa thèse de 1932 intitulée " De la psychose paranoïaque dans ses rapports avec la personnalité ", Jacques Lacan critique, de façon éparpillée dans le texte de sa thèse, le parallélisme psychophysique soutenu par la tradition psychiatrique. Dans ce contexte et comme clé pour expliquer à la fois les psychoses paranoïaques et la paranoïa auto-punissant du cas Aimée, le jeune psychiatre présentera sa propre version du parallélisme, basée sur deux auteurs : Jakob Von Uexküll et Baruch Spinoza. Cet article met en évidence cette entreprise, ainsi que les conséquences d'un parallélisme proprement lacanien.

Mots clés: Parallélisme, psychose, Umwelt, discordance

(Die Kritik des jungen Lacans am psychophysischen Parallelismus in „Über die paranoische Psychose in ihren Beziehungen zur Persönlichkeit und Frühe Schriften über die Paranoia“)

In seiner 1932 verfassten Doktorarbeit , Über die paranoische Psychose in ihren Beziehungen zur Persönlichkeit und Frühe Schriften über die Paranoia“ kritisiert Jacques Lacan wiederholt den psychophysischen Parallelismus, der damals von der psychiatrischen Tradition vertreten wurde. In diesem Zusammenhang und als Schlüssel zur Erklärung sowohl der paranoiden Psychosen als auch der selbstbestrafenden Paranoia des Falles Aimée entwickelt der junge Psychiater eine eigene Version des Parallelismus, welche auf zwei Autoren basiert, Jakob von Uexküll 


\section{ARTIGOS}

und Baruch Spinoza. Dieser Artikel beschreibt diesen Entwicklungsprozess und die Konsequenzen des Lacanianischen Parallelismus.

Schlüsselwörter: Parallelismus, Psychose, Umwelt, Diskordanz

Citação/Citation: Coloma Arenas, M. (2019, setembro). La crítica del joven Lacan al paralelismo psicofísico en "De la Psicosis Paranoica en sus relaciones con la personalidad". Revista Latinoamericana de Psicopatologia Fundamental, $22(3), 497-519$ http://dx.doi. org/10.1590/1415-4714.2019v22n3p497.6.

Editora/Editor: Profa. Dra. Ana Maria R. G. Oda

Submetido/Submitted: 18.4.2019 / 4.18.2019 Versão revisada/Revised Date: 4.6.2019 / 6.4.2019

Aceito/Accepted: 9.6.2019 / 6.9.2019

Copyright: (C) 2009 Associação Universitária de Pesquisa em Psicopatologia Fundamental/ University Association for Research in Fundamental Psychopathology. Este é um artigo de livre acesso, que permite uso irrestrito, distribuição e reprodução em qualquer meio, desde que o autor e a fonte sejam citados / This is an open-access article, which permits unrestricted use, distribution, and reproduction in any medium, provided the original authors and sources are credited.

Financiamento/Funding: Este trabalho não recebeu apoio / This work received no funding.

Conflito de interesses/Conflict of interest: $\mathrm{O}$ autor declara que não há conflito de interesses

\section{Manuel Coloma Arenas}

Psicólogo; Magíster psicologia clínica;Magíster en psicoanálisis; Doctor C en psicoanálisis. Universidad Andrés Bello

Carrera de Psicología, sede Viña del Mar

Quillota 980

mcoloma@unab.cl

manuelcolomaarenas@hotmail.com

https://orcid.org/0000-0002-4205-7473

This is an open-access article, which permits unrestricted use, distribution,

\section{(cc) BY-NC} and reproduction in any medium for non-commercial purposes provided the original authors and sources are credited. 